\title{
Pseudomyxoma peritonei due to low-grade appendiceal mucinous neoplasm with symptoms of inguinal hernia and uterine prolapse: a case report and review of the literature
}

\author{
Hideki Watanabe $^{1}$ - Yoshiaki Miyasaka ${ }^{1}$ Kana Watanabe ${ }^{2}$ Ikuko Sakamoto $^{2}$. \\ Hiroshi Nakagomi ${ }^{1}$ - Atsushi Takano ${ }^{1}$. Kou Ikegame ${ }^{1} \cdot$ Atsushi Yamamoto $^{1}$. \\ Haruka Nakada ${ }^{1} \cdot$ Michiya Yasutome $^{1} \cdot$ Kazushige Furuya $^{1} \cdot$ Masao Hada $^{1}$. \\ Masayuki Inoue $^{1} \cdot$ Toshio Oyama $^{3}$
}

Received: 20 January 2017/ Accepted: 25 April 2017/Published online: 13 May 2017

(c) The Author(s) 2017. This article is an open access publication

\begin{abstract}
Pseudomyxoma peritonei (PMP) is an unusual condition in which massive amounts of mucinous ascites in conjunction with mucinous peritoneal and omental implants occur. We herein report a case of PMP due to low-grade appendiceal neoplasm (LAMN) and a literature review to clarify the clinical features of PMP. A 68-year-old female suffered from anorexia and abdominal distension and was referred to the emergency department of our hospital. Rightside inguinal hernia and uterine prolapse were revealed by a physical examination. Abdominal computed tomography at admission indicated massive ascites and a ruptured cystic mass in the lower-right abdomen. We diagnosed the patient with a ruptured appendiceal mucinous adenoma and PMP and scheduled a laparotomy. We performed an appendectomy containing the cystic mass, bilateral oophorectomy, and a biopsy for the peritoneum. We irrigated the abdominal cavity using $3000 \mathrm{ml}$ of dextran solution. The macroscopic findings showed a ruptured cystic mass measuring $5 \times 4 \mathrm{~cm}$ arising from the middle of the appendix. The bilateral ovaries and peritoneum were also covered with yellow mucin. The pathologic findings revealed the presence of low-grade atypical cells inside the capsule. However, no tumor cells were found on the surface of the ovary or peritoneum. A literature review revealed that the prognosis of PMP due to LAMN is relatively good, with a 5-year survival rate of $80 \%$, and hernia
\end{abstract}

Hideki Watanabe

h-watanabe1326@ych.pref.yamanashi.jp

1 Department of Surgery, Yamanashi Prefectural Central Hospital, 1-1-1 Fujimi, Kofu, Yamanashi 400-8506, Japan

2 Department of Gynecology, Yamanashi Prefectural Central Hospital, Kofu, Japan

3 Department of Pathology, Yamanashi Prefectural Central Hospital, Kofu, Japan is occasionally caused by PMP. According to this literature review, we knew this case might be a typical case. However, PMP is very rare; we need further follow-up data to select an optimal treatment for preventing the relapse of PMP.

Keywords Pseudomyxoma peritonei · Low-grade appendiceal mucinous neoplasm · Inguinal hernia $\cdot$ Uterine prolapse

\section{Background}

Pseudomyxoma peritonei (PMP) is an unusual condition in which massive amounts of mucinous ascites in conjunction with mucinous peritoneal and omental implants occur [1]. The majority of PMP cases are considered to originate from the appendix and ovary, and occasionally arise from mucinous adenocarcinoma of various organs, such as the colorectum, fallopian tube, gallbladder, urachs, and pancreas [2-5], while in the low-grade or high-grade mucinous neoplasm, the appendix is the primary site in the great majority of cases [1]. Regarding cases with PMP involving both appendix and ovary, the consensus is that the primary site is the appendix, with the ovaries the secondary site, excluding special cases [6-11].

The incidence of PMP is very low; it is estimated to occur in 2 out of 10,000 laparotomies [12]. Therefore, the clinical features have not been well described. Although surgical debulking and appendectomy are considered adequate for initial therapy [1], the etiology, predictive factors of recurrence, and significance of anti-cancer therapies remain to be clarified.

We herein report a case of PMP due to low-grade appendiceal neoplasm and review the literature to clarify the clinical features of PMP. 

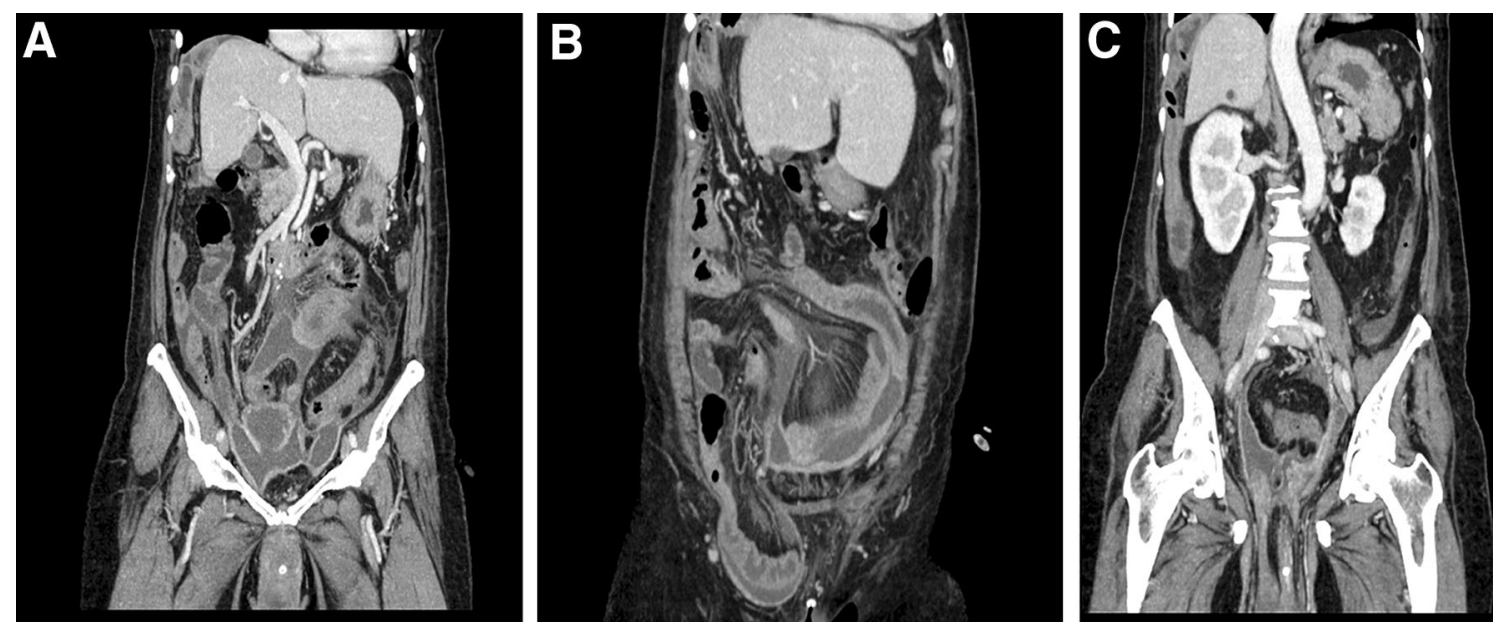

Fig. 1 Computed tomography (CT) findings at admission. Coronial view shows massive ascites and a cystic mass in the lower-right abdomen that ruptured to abdominal cavity (a). CT also revealed a right inguinal hernia containing the small intestine (b) and uterine prolapse (c)

\section{Case report}

A 68-year-old female was referred to the emergency department of our hospital in April 2016. She was suffering from anorexia, abdominal distension, abdominal pain in lower-right abdomen. Furthermore, a right-side inguinal hernia and uterine prolapse were revealed by a physical examination. Her height and weight were $154 \mathrm{~cm}$ and $65 \mathrm{~kg}$, respectively, and she had no history of other diseases.

Laboratory data showed inflammatory changes, as indicated by a white blood cell count of $13,600 / \mu 1$, CRP of $33.8 \mathrm{mg} / \mathrm{dl}$, hypoalbuminemia at the serum albumin level $3.4 \mathrm{~g} / \mathrm{dl}$, and slight renal dysfunction (BUN $108 \mathrm{mg} / \mathrm{dl}$, Creatinine $4.25 \mathrm{mg} / \mathrm{dl}$ ); in addition, she had elevated levels of tumor markers CEA, CA19-9 and CA125 at $37 \mathrm{ng} / \mathrm{ml}$, $113 \mathrm{U} / \mathrm{ml}$, and $124 \mathrm{U} / \mathrm{ml}$, respectively.

Abdominal computed tomography (CT) at admission revealed massive ascites and a cystic mass in the lowerright abdomen that ruptured to abdominal cavity (Fig. 1a). The CT density of the ascites was 10-20 Hounsfield units (H.U.) which was higher than serous ascites (0-5 H.U.) CT also revealed a right inguinal hernia containing the small intestine (Fig. 1b) and uterine prolapse (Fig. 1c). Magnetic resonance imaging revealed that the cystic tumor was arising from appendix (Fig. 2). We had aspirated the ascites being yellow and cloudy. And cytology of the ascites showed mucus suggesting the diagnosis of PMP but no malignant cells (Fig. 3).

Based on these findings, we diagnosed the patient with ruptured appendiceal mucinous adenoma and PMP and scheduled a laparotomy. Massive yellow and cloudy ascites and ruptured cystic tumor arising from the appendix were seen (Fig. 4a). Bilateral ovaries and peritoneum were covered with the yellow substance. We performed an

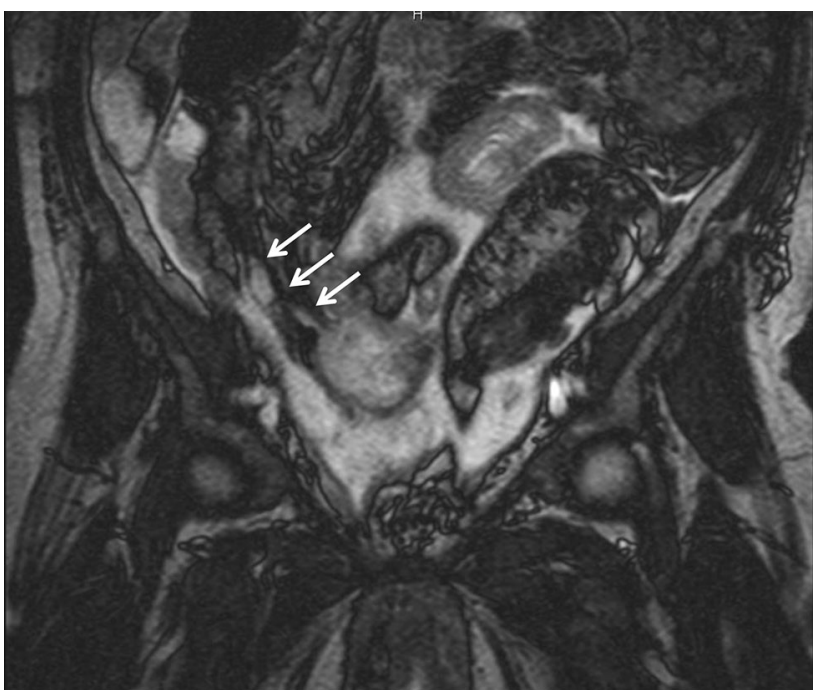

Fig. 2 Magnetic resonance imaging (MRI) findings. A cystic tumor is arising from the appendix

appendectomy containing the cystic mass, bilateral oophorectomy and a biopsy for the peritoneum. We irrigated the abdominal cavity using $3000 \mathrm{ml}$ of dextran solution.

Additionally, we fixed the pelvic diaphragm by sutures and repaired the inguinal hernia via the another incision.

The macroscopic findings showed a ruptured cystic mass measuring $5 \times 4 \mathrm{~cm}$ arising from the middle of the appendix. We also noted small nodules inside the capsule. Mucous was retained in the vermis. The bilateral ovaries and peritoneum were also covered with yellow mucin. The pathologic findings revealed the presence of low-grade atypical cell inside the capsule, and fibrosis with hemosiderin and cholesterin was observed in the wall of the vermis (Fig. 5) . However, no tumor cells were found on the surface of the ovary or peritoneum. 


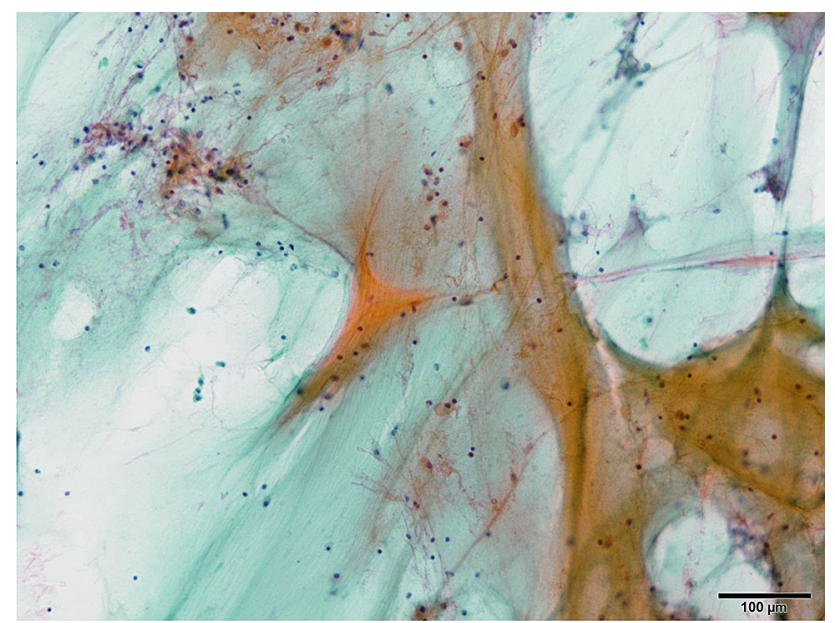

Fig. 3 Cytology of the ascites. Mucus indicated the diagnosis of PMP but no malignant cells are seen

The postoperative course was uneventful, and the serum tumor marker levels subsequently decreased to CEA $3.1 \mathrm{ng} / \mathrm{ml}$, CA19-9 47.6 U/ml, and CA125 $17.7 \mathrm{U} / \mathrm{ml}$, 2 months later.

We administered S1 $(75 \mathrm{mg} /$ body for 14 days every 21 days) to prevent the relapse. The patient is doing well in 1 year later.

\section{Discussion and review of the literature}

PMP is a complex disease with unique biological behavior that usually arises from appendiceal mucinous neoplasia. The classification of PMP and its primary appendiceal neoplasm has been discussed and the terminology has changed [13]. In 2010, the WHO proposed the classification of appendiceal mucinous tumors and PMP based on the presence of mucin, and the cytological and architectural features [14]. According to the WHO classification, appendiceal mucinous tumors (excluding signet cell carcinoma) are now divided into two categories: low-grade appendiceal mucinous neoplasm (LAMN) and mucinous adenocarcinoma (MACA). This has been the common classification thus far.

The WHO also defined two categories for PMP as well: low grade and high grade; however, the terms of disseminated peritoneal adenomucinosis (DPAM), peritoneal mucinous carcinoma (PMCA) and discordant type are also allowed. Indeed, PMP with intermediate atypical cells and discordant type is categorized as PMCA-I/D in other reports [13]. Furthermore, it still be controversial whether or not PMP with acellular mucin should be classified separately [13].

The present case was diagnosed as LAMN and acellulartype PMP, and its special clinical features were accompanied by the symptoms of inguinal hernia and uterine prolapse, renal dysfunction and elevated level of tumor markers, such as CEA and CA125.

Adequate follow-up data are required for understanding of the etiology, predictive factors of recurrence, and efficacy of anti-cancer therapies. Therefore, we reviewed 4 cohort studies containing around 100 cases of appendiceal neoplasm with PMP. We also reviewed 15 Japanese case reports with PMP presenting with symptoms of hernia, and anal prolapse, cited in Japan MEDLINE from 1988 to 2014.

For the cohort studies, we reviewed the age at PMP development, gender, pathology, and survival rates. The mean age at the development of PMP was almost the same across all four studies, at around 50 years old (Table 1), with no significant differences observed between LAMN and PMCA (data not shown). Gender differences were observed in only one report [9] that showed 86 females versus 21 males. However, this
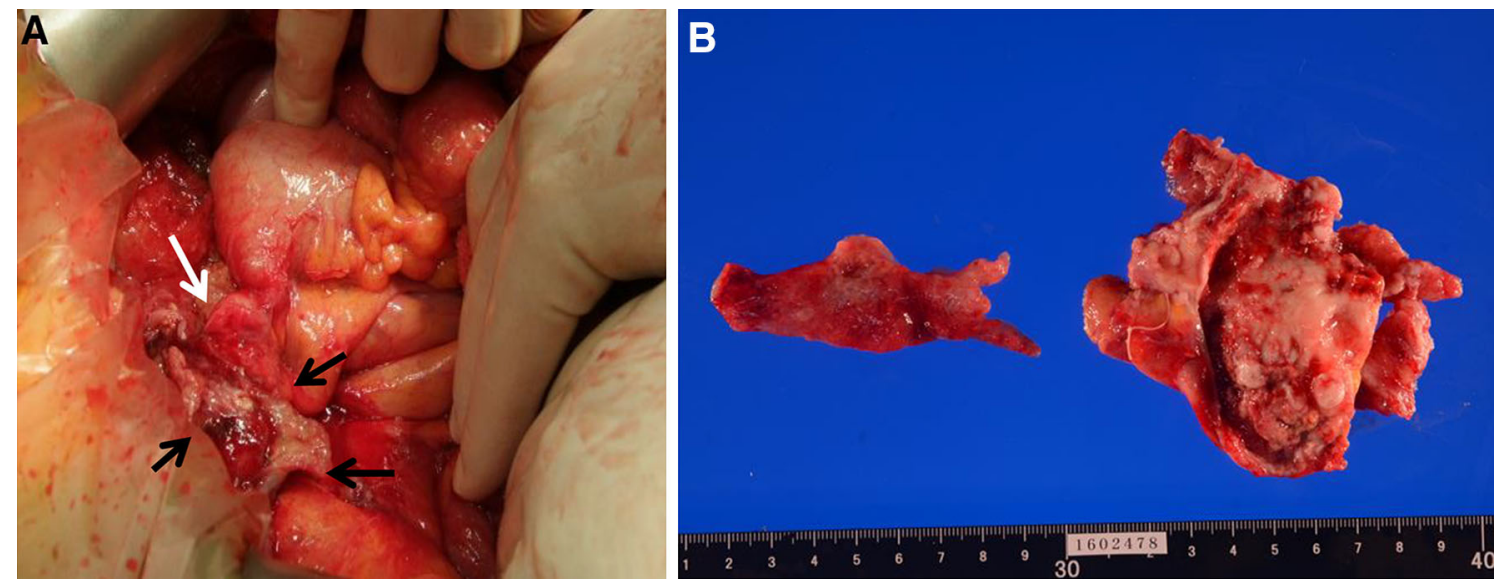

Fig. 4 Operative and macroscopic findings of appendix. A ruptured cystic mass measuring $5 \times 4 \mathrm{~cm}$ is arising from the middle of the appendix (black arrow). We also noted small nodules inside the capsule. Mucous is retained in the vermis 

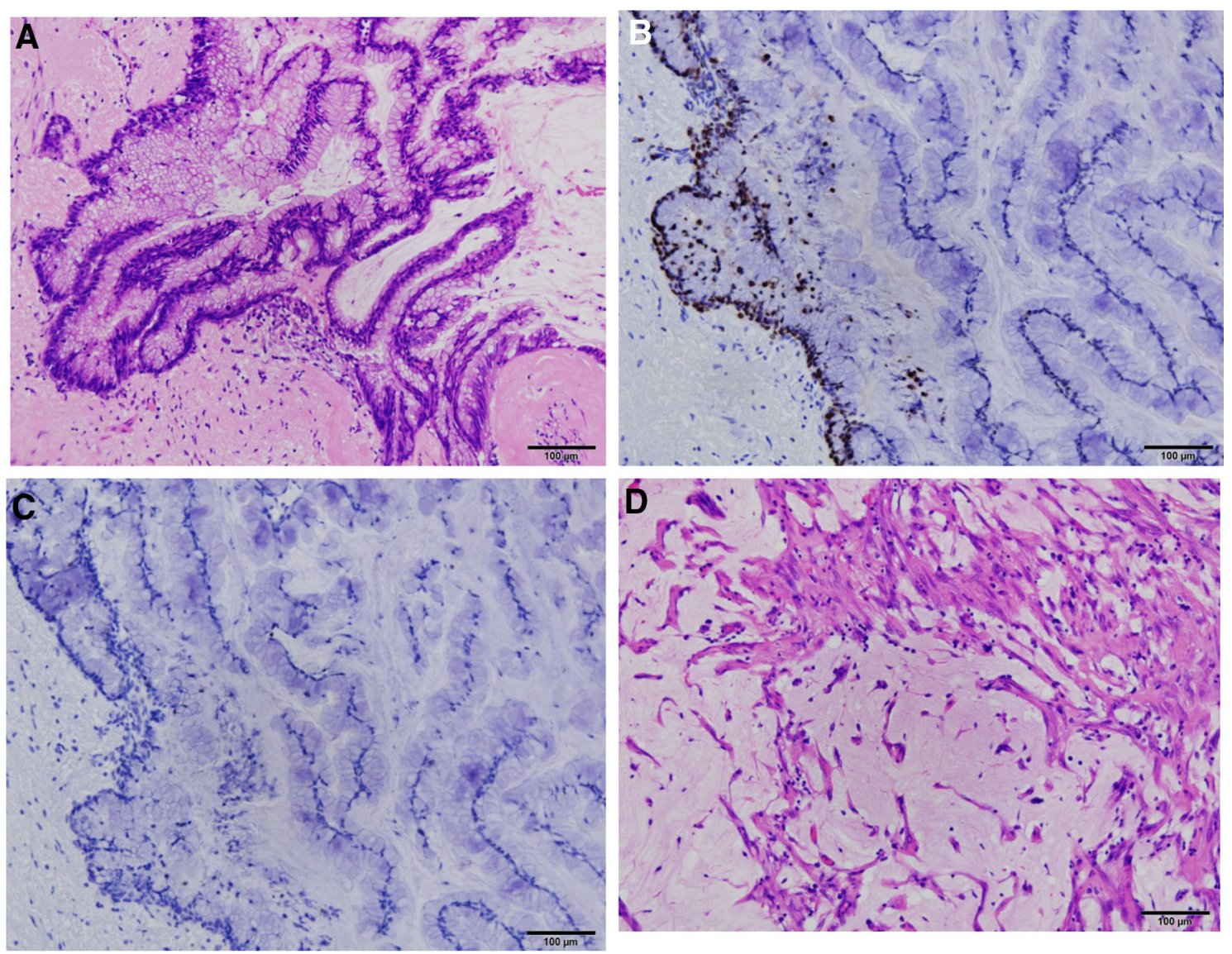

Fig. 5 The pathologic findings. HE staining (a) shows the presence of low-grade atypical cells inside the capsule which are producing mucin. Immuno-histochemical staining shows high labeling index of

Ki 67 (b) and no expression of P53 (c). While, no tumor cells were found on the surface of the ovary $(\mathbf{d})$

Table 1 Review of the cohort studies for pseudomyxoma due to appendical mucinous neoplasma

\begin{tabular}{|c|c|c|c|c|c|c|c|c|c|c|}
\hline \multirow[t]{2}{*}{ Authors (year) } & \multirow[t]{2}{*}{ No. of cases } & \multirow[t]{2}{*}{ Mean age } & \multicolumn{2}{|c|}{ Gender } & \multicolumn{3}{|c|}{ Appendical mucinous tumor } & \multicolumn{3}{|c|}{ Pseudomyxoma peritonei } \\
\hline & & & Male & Female & LAMN & Discordant & MACA & DPAM & PMCA-I/D & PMCA \\
\hline Ronnett (1995) [6] & 109 & 51 & 65 & 44 & nd & nd & nd & 65 & 14 & 30 \\
\hline Misdraji (2003) [9] & $107(50)^{\mathrm{a}}$ & 54 & 21 & 86 & 88 & 3 & 16 & 39 & 3 & 8 \\
\hline Bradley (2006) [6] & 101 & 50 & 45 & 56 & nd & nd & nd & 58 & 20 & 23 \\
\hline Guo (2012) [11] & 92 & 53 & 45 & 47 & nd & nd & nd & 49 & 26 & 17 \\
\hline Sum of cases & 352 & & & & & & & $211(60 \%)$ & $63(18 \%)$ & $78(22 \%)$ \\
\hline
\end{tabular}

LAMN low-grade appendiceal mucinous neoplasm, MACA mucinous adenocarcinoma, DPAM disseminated peritoneal adenomucinosis, $P M C A$ peritoneal mucinous carcinomatosis, $-I / D$-intermediate/discordant, $n d$ not documented

a 50 cases developed pseudomyxoma peritonei, among 107 cases with appendicial neoplasm

difference was not seen in the other three reports. Mistrali et al. reported that PMP occurred in $44 \%$ (39/88) of LAMN and 50\% (8/16) of MACA patients [9]. While, the incidences of DPAM, PMCA-I/D, and PMCA were 60, 18 , and $22 \%$, respectively, across the four reports (although the categories of PMCA-I/D differed slightly among these reports).

Regarding the survival, Guo et al. reported that (3-, 5-, 10-year survival rates) of DPMA, PMCA-I/D and PMCA are $(97,80,65) \%,(80,67,28) \%$, and $(67,50,14) \%$, 
Table 2 Literature review of 15 cases with PMP developed the symptom of hernia or etc

\begin{tabular}{|c|c|c|c|c|c|c|c|c|c|}
\hline \multirow[t]{2}{*}{ No. } & \multirow[t]{2}{*}{ Authors } & \multirow[t]{2}{*}{ Year } & \multirow[t]{2}{*}{ Gender } & \multirow[t]{2}{*}{ Age } & \multirow{2}{*}{$\begin{array}{l}\text { Site of hernia } \\
\text { and prolapse }\end{array}$} & \multicolumn{2}{|l|}{ Histology } & \multirow{2}{*}{$\begin{array}{l}\text { CEA } \\
(\mathrm{ng} / \mathrm{ml})\end{array}$} & \multirow[t]{2}{*}{ Additional therapy } \\
\hline & & & & & & $\begin{array}{l}\text { Appendiceal } \\
\text { tumor }\end{array}$ & PMP & & \\
\hline 1 & Imai [18] & 1988 & Male & 53 & $\mathrm{rt}$ ing & LAMN & DPMN & 1.4 & OK432 ip/UFT po \\
\hline 2 & Yamamoto [19] & 1989 & Male & 62 & lt ing & LAMN & DPMN & 13.2 & MMC ip/Tegafur po \\
\hline 3 & Matsuda [20] & 1996 & Male & 55 & $\mathrm{rt}$ ing & LAMN & acellular mucin & nd & nd \\
\hline 4 & Iguchi [21] & 1999 & Male & 74 & bil ing & LAMN & DPMN & nd & MMC ip \\
\hline 5 & Uchida [22] & 2000 & Female & 80 & $\mathrm{rt} \mathrm{fem}$ & LAMN & nd & 4.4 & nd \\
\hline 6 & Yano [23] & 2000 & Male & 31 & lt ing & MACA & PMCA & 76.6 & Dextran/CDDP ip \\
\hline 7 & Tanaka [24] & 2001 & Male & 73 & $\mathrm{rt}$ ing & LAMN & DPMN & 9.2 & nd \\
\hline 8 & Uchiyama [25] & 2004 & Female & 76 & Umbilical & MACA & PMCA & 12 & nd \\
\hline 9 & Ohtani [26] & 2005 & Female & 80 & Anal prolapse & na & PMCA (ovarian) & 27 & nd \\
\hline 10 & Shinohara [27] & 2006 & Male & 55 & lt ing & na & PMCA (urachs) & Normal & Dextran/5'DFUR po \\
\hline 11 & Toriguchi [28] & 2011 & Male & 67 & $\mathrm{rt}$ ing & LAMN & Acellular mucin & 2 & nd \\
\hline 12 & Hamaguchi [29] & 2012 & Male & 70 & ing & LAMN & DPMN & 9 & $\mathrm{LV} / 5 \mathrm{FU}$ \\
\hline 13 & Kubo [30] & 2012 & Male & 42 & lt Ing & LAMN & DPMN & 25 & dextran \\
\hline 14 & Fujita [31] & 2014 & Male & 54 & lt ing & LAMN & DPMN & nd & HIPEC \\
\hline 15 & Presented case & & Female & 76 & lt ing/uterine prolapse & LAMN & Acellular mucin & 37 & Dextran/S1po \\
\hline
\end{tabular}

$r t$ Right, $l t$ left, bil bilateral, ing inguinal hernia, fem: femoral hernia, ip intraperitoneal administration, $p o$ oral administration, $n d$ not documented, $L A M N$ low-grade appendiceal mucinous neoplasm, MACA mucinous adenocarcinoma, DPAM disseminated peritoneal adenomucinosis, $P M C A$ peritoneal mucinous carcinomatosis, $L V$ leucovorin, HIPEC hyperthermic interperitoneal chemotherapy, MMC mytomicyn C, CDDP cisplatin, $5 F U$ fluorouracil, $5^{\prime} D F U R$ doxifluridine, $n d$ not documented, $n a$ not applicable

respectively [11]. The prognosis of PMCA was significantly worse than that of DPMA and PMCA-I/D. Several authors have described a good prognosis of ruptured LMCA with PMP containing scant epithelial cells just like the present case $[13,15]$. These cases were included in the DPMA cases in these cohort studies.

There were 14 cases with symptoms of hernia or prolapse, cited in Japanese MEDLINE from 1988 to 2014: 11 cases of inguinal hernia, one of femoral hernia, umbilical hernia, and anal prolapse (Table 2). The present case developed both inguinal hernia and uterine prolapse (Table 1). The mean age $( \pm \mathrm{SD})$ was $63 \pm 15$ years old, and there were far more male cases than females (11 vs 4). Four cases were PMCA, 7 DPMN, 3 acellular mucin and 1 unknown. Serum CEA was elevated more than $5 \mathrm{ng} / \mathrm{ml}$ in 3/4 of PMCA and 4/10 of DPMN and acellular mucin. Most of all cases received irrigation and additional therapy such as intraperitoneal administration of anti-cancer drugs, OK432, Mitomycin C, Cisplatin, dextran solution, 5\% glucose. Although the effect of hyperthermic intraperitoneal chemotherapy (HIPEC) for PMP [16] and new therapeutic effort was reported for MACA [17], we have no evidences in primary chemotherapy for LMCA. Considering the good prognosis of LMCA, systemic chemotherapy could be reserved for patients with proven recurrence. However, we have no guidelines for systemic therapies for PMP; further follow-up data are necessary to select the optimal treatment.

\section{Conclusions}

We experienced a case of PMP due to LAMN that involved symptoms of right inguinal hernia and uterine prolapse. A literature review showed that the prognosis of PMP due to LAMN is relatively good with a 5-year survival rate of $80 \%$, and hernia is occasionally caused by PMP. However, we need further follow-up data to accurately predict the prognosis of PMP.

\section{Compliance with ethical standards}

Conflict of interest The authors declare no conflicts of interest (COI).

Informed consent Written informed consent was obtained from the patient for publication of this case and any accompanying images.

Authors contribution HW, HN, and TO conceived of this case presentation and drafted the manuscript. YM, KW, IS, AT, KI, AY, $\mathrm{HN}, \mathrm{MY}, \mathrm{KF}, \mathrm{MI}$ and MH participated in the treatment of this case. All authors read and approved the final manuscript.

Open Access This article is distributed under the terms of the Creative Commons Attribution 4.0 International License (http://crea tivecommons.org/licenses/by/4.0/), which permits unrestricted use, distribution, and reproduction in any medium, provided you give appropriate credit to the original author(s) and the source, provide a link to the Creative Commons license, and indicate if changes were made. 


\section{References}

1. Sherer DM, Abulafia O, Eliakim R (2001) Pseudomyxoma peritonei: a review of current literature. Gynecol Obstet Invest 51:73-80

2. Costa MJ (1994) Pseudomyxoma peritonei. Histologic predictors of patient survival. Arch Pathol Lab Med 118:1215-1219

3. Kurita M, Komatsu H, Hata Y et al (1994) Pseudomyxoma peritonei due to adenocarcinoma of the lung: case report. J Gastroenterol 29:344-348

4. McCarthy JH, Aga R (1988) A fallopian tube lesion of borderline malignancy associated with pseudo-myxoma peritonei. Histopathology 13:223-225

5. Zanelli M, Casadei R, Santini D et al (1998) Pseudomyxoma peritonei associated with intraductal papillary-mucinous neoplasm of the pancreas. Pancreas 17:100-102

6. Ronnett BM, Kurman RJ, Zahn CM et al (1995) Pseudomyxoma peritonei in women: a clinicopathologic analysis of 30 cases with emphasis on site of origin, prognosis, and relationship to ovarian mucinous tumors of low malignant potential. Hum Pathol 26:509-524

7. Prayson RA, Hart WR, Petras RE (1994) Pseudomyxoma peritonei. A clinicopathologic study of 19 cases with emphasis on site of origin and nature of associated ovarian tumors. Am J Surg Pathol 18:591-603

8. Ronnett BM, Zahn CM, Kurman RJ et al (1995) Disseminated peritoneal adenomucinosis and peritoneal mucinous carcinomatosis. A clinicopathologic analysis of 109 cases with emphasis on distinguishing pathologic features, site of origin, prognosis, and relationship to "pseudomyxoma peritonei". Am J Surg Pathol 19:1390-1408

9. Misdraji J, Yantiss RK, Graeme-Cook FM et al (2003) Appendiceal mucinous neoplasms: a clinicopathologic analysis of 107 cases. Am J Surg Pathol 27:1089-1103

10. Bradley RF, Stewart JHT, Russell GB et al (2006) Pseudomyxoma peritonei of appendiceal origin: a clinicopathologic analysis of 101 patients uniformly treated at a single institution, with literature review. Am J Surg Pathol 30:551-559

11. Guo AT, Li YM, Wei LX (2012) Pseudomyxoma peritonei of 92 Chinese patients: clinical characteristics, pathological classification and prognostic factors. World J Gastroenterol 18:3081-3088

12. Mann WJ Jr, Wagner J, Chumas J et al (1990) The management of pseudomyxoma peritonei. Cancer 66:1636-1640

13. Carr NJ, Cecil TD, Mohamed F et al (2016) A consensus for classification and pathologic reporting of pseudomyxoma peritonei and associated appendiceal neoplasia: the results of the peritoneal surface oncology group International (PSOGI) modified Delphi process. Am J Surg Pathol 40:14-26

14. Carr NJ, Sobin LH. Adenocarcinoma of the appendix

15. Smith JW, Kemeny N, Caldwell C et al (1992) Pseudomyxoma peritonei of appendiceal origin. The Memorial Sloan-Kettering Cancer Center experience. Cancer 70:396-401

16. Verwaal VJ, van Ruth S, de Bree E et al (2003) Randomized trial of cytoreduction and hyperthermic intraperitoneal chemotherapy versus systemic chemotherapy and palliative surgery in patients with peritoneal carcinomatosis of colorectal cancer. J Clin Oncol 21:3737-3743

17. Loungnarath R, Causeret S, Bossard N et al (2005) Cytoreductive surgery with intraperitoneal chemohyperthermia for the treatment of pseudomyxoma peritonei: a prospective study. Dis Colon Rectum 48:1372-1379

18. Imai H, Kimoto M, Nagano H, et al (1988) A case of pseudomyxoma peritonei originating from the vvermiform appendix found incidentally at operation on a right inguinal hernia. Kawasaki Igakukaishi 14:645-649 (in Japanese)

19. Yamamoto H, Kaneko I, Noura M et al (1989) Pseudomyxoma peritonei discovered during operation for the inguinal hernia: a case report. J Takayama Red Cross Hospital 13:99-103 (in Japanese)

20. Matsuda M, Adachi S, Morishima Y et al (1996) Psedomyxoma peritonei appearing as inguinal hernia. Jpn J Gastroenterological Surg 29:99-103 (in Japanese)

21. Iguchi T, Nagai N, Takahashi M et al (1999) A case of pseudomyxoma peritonei appearing as inguinal hernia. Surg Ther 80:506-508 (in Japanese)

22. Uchida M, Kimoto K, Ohno S, et al (2000) Three cases of mucinous cyst adenoma of the appendix presented with different processes. J Jpn Surg Assoc 61:995-999 (in Japanese)

23. Yano F, Komura N, Kashiwagi H, et al (2000) A case of pseudomyxoma peritonei originating from the vermiform appendix found incidentally at the operation on an inguinal hernia. Geka 62:831-833 (in Japanese)

24. Tanaka R, Machiki Y, Takuna N et al (2000) Pseudomyxoma peritonei appearing as inuina hernia. Rinnshougeka 56:849-851 (in Japanese)

25. Uchiyama T, Onoji S, Watanabe K, et al (2004) A case of pseudomyxoma peritonei found on the occurrence of an adult umbilical hernia. Geka 66:243-246 (in Japanese)

26. Ohtani S, Okano K, Hamahuku R (2005) The diseases with ascites developed anal prolapse. Tottori Med J 33:112-113 (in Japanese)

27. Shinohara S, Misawa K, Sano H et al (2006) Pseudomyxoma peritonei due to mucinous cystadenocarcinoma in situ of the urachs presemting as an inguinal hernia. Int $\mathrm{J}$ Clin Oncol $11: 416-419$

28. Toriguchi H, Endo S, Tubono M (2011) A case of metachronous mucinous cystadenoma of the appendix occurring after resection of an inguinal canal mucinous tumor. J Jpn Surg Assoc 72:916-920 (in Japanese)

29. Hamaguchi J, Shinohara T, Maeda Y et al (2012) A case of pseudoperitonei presented with an inguinal hernia. J Jpn Surg Assoc 73:2755-2729 (in Japanese)

30. Kubo N, Nakayama C, Takauchi N, et al (2012) A case of pseudomyxoma peritonei incidentally discovered during an inguinal hernio-plasty. Rinnshogeka 67:571-574 (in Japanese)

31. Fujita Y, Michikiyo T, Yoshira T (2014) A case of pseudomyxoma peritonei presented with an inguinal hernia. J Nissei Hospital 42:24-27 (in Japanese) 